\title{
Recovery of a Burkholderia thailandensis-like isolate from an Australian water source
}

\author{
Jay E Gee*1, Mindy B Glass ${ }^{1}$, Ryan T Novak², Daniel Gal2 ${ }^{2}$, Mark J Mayo², \\ Arnold G Steigerwalt ${ }^{1}$, Patricia P Wilkins ${ }^{1}$ and Bart J Currie ${ }^{2}$
}

\begin{abstract}
Address: ${ }^{1}$ Bacterial Zoonoses Branch, Division of Foodborne, Bacterial, and Mycotic Diseases, National Center for Zoonotic, Vector-Borne, and Enteric Diseases, Centers for Disease Control and Prevention, 1600 Clifton Rd., NE., MS-G34, Atlanta, Georgia, 30333, USA and 2Menzies School of Health Research, Charles Darwin University, Darwin, Northern Territory, Australia

Email: Jay E Gee* - JGee1@cdc.gov; Mindy B Glass - wzg0@cdc.gov; Ryan T Novak - bnk4@cdc.gov; Daniel Gal - daniel.gal@internode.on.net; Mark J Mayo - Mark.Mayo@menzies.edu.au; Arnold G Steigerwalt - ags1@cdc.gov; Patricia P Wilkins - pma1@cdc.gov;

Bart J Currie - bart@menzies.edu.au

* Corresponding author
\end{abstract}

Published: 2 April 2008

BMC Microbiology 2008, 8:54 doi:10.1 |86/147|-2180-8-54
Received: 8 August 2007

Accepted: 2 April 2008

This article is available from: http://www.biomedcentral.com/l47I-2/80/8/54

(C) 2008 Gee et al; licensee BioMed Central Ltd.

This is an Open Access article distributed under the terms of the Creative Commons Attribution License (http://creativecommons.org/licenses/by/2.0), which permits unrestricted use, distribution, and reproduction in any medium, provided the original work is properly cited.

\begin{abstract}
Background: Burkholderia thailandensis, a close relative of Burkholderia pseudomallei, has previously been reported only from Southeast Asia and North America. It is biochemically differentiated from B. pseudomallei by the ability to utilize arabinose. During the course of environmental sampling for B. pseudomallei in the Northern Territory of Australia, an isolate, MSMB 43, was recovered that is arabinose positive.

Results: Genetic analysis using I6S rDNA sequencing and DNA/DNA hybridization indicates that MSMB 43 is most similar to $B$. thailandensis although multi-locus sequence typing indicates that this isolate is divergent from both $B$. pseudomallei and other described $B$. thailandensis.
\end{abstract}

Conclusion: We report the isolation and initial characterization of strain MSMB 43, which is a $B$. thailandensis-like isolate recovered in Australia.

\section{Background}

Burkholderia thailandensis is a less virulent close relative of Burkholderia pseudomallei, the causative agent of melioidosis [1]. B. thailandensis can be differentiated biochemically from $B$. pseudomallei by its ability to assimilate arabinose $[1,2]$. During the course of environmental surveys for $B$. pseudomallei in the rural region outside Darwin, Northern Territory, Australia, an arabinose assimilating isolate, designated strain MSMB 43, was recovered from a bore water source that also yielded $B$. pseudomallei from the same and subsequent samples.
We report the initial characterization of a B. thailandensislike isolate, the first of its kind, in Australia. In this study we characterize strain MSMB 43 using phenotypic tests, 16S rDNA gene sequencing, multi-locus sequence typing (MLST), and DNA-DNA hybridization.

\section{Results and Discussion}

Standard biochemical testing, including arabinose assimilation, identified strain MSMB 43 as B. thailandensis. However, MSMB 43 did not grow at $42^{\circ} \mathrm{C}$ and produced little to no gas from nitrate $[1,3]$. A B. pseudomallei-specific real-time PCR method targeting a gene in the type III secretion system (TTS) was performed as previously 
described. Strain MSMB 43 was negative by TTS real-time PCR suggesting that it was not a $B$. pseudomallei [4].

The accession numbers for the 16S rDNA sequences determined for strains MSMB 43 and Burkholderia thailandensis ATCC $700388^{\mathrm{T}}$ are [GenBank: EF114404] and [GenBank: EF535235] respectively. The $16 \mathrm{~S}$ rDNA sequence of strain MSMB 43 has $99.7 \%$ similarity and $98.9 \%$ identity to the $16 \mathrm{~S}$ rDNA sequence of the $B$. thailandensis type strain. The discrepancy between the \% similarity and \% identity is due to multiple heterogeneous base calls in the sequence for MSMB 43, probably resulting from differences in alleles of the 16S rDNA, which has been previously noted for B. pseudomallei, but not in B. thailandensis $[1,5]$.

To characterize MSMB 43 further, we performed multilocus sequence typing (MLST), which uses the DNA sequencing of defined segments of seven housekeeping genes to determine strain relatedness [6]. Strain MSMB 43 was assigned a sequence type (ST) of 318 on the MLST website. None of the alleles for strain MSMB 43 matched alleles of $B$. thailandensis strains available in the MLST database [7]. A dendrogram using concatenated sequences of all $B$. thailandensis STs in the database, along with a representative set of $B$. pseudomallei and B. oklahomensis sequences, indicates that ST 318 of strain MSMB 43 does not cluster with any STs except for ST475 (Fig. 1). ST475 is represented by only one example, strain 1554, which is an unassigned Burkholderia species from a water sample from another bore in the rural Darwin region that had also yielded B. pseudomallei isolates. MSMB 43 and strain 1554 share one allele, narK, by MLST. Comparing the concatenated sequences directly indicates that the sequence for ST 318 has an identity of $96.8 \%, 96.3 \%$, and $95.6 \%$, respectively, to the sequences of the type strains of B. thailandensis, B. pseudomallei, and B. oklahomensis.

To determine the relatedness of strain MSMB 43 to the $B$. thailandensis type strain at the whole genome level DNADNA hybridization was performed as previously described $[8,9]$. A $91 \%$ level of relatedness was determined when DNA from strain MSMB 43 was labeled and in the reciprocal test using labeled DNA from the B. thailandensis type strain (Table 1).

Burkholderia pseudomallei is a major cause of community acquired septicemia in Thailand and in tropical northern Australia, especially the Darwin region of the Northern Territory $[10,11]$. As an environmental saprophyte, it has a wide distribution in endemic areas and poses a hazard for those who are exposed to it. In northern Australia, the ability to distinguish the pathogen $B$. pseudomallei from less or non-pathogenic species is important since public health action may result $[4,5,9,10]$. For instance, the misidentification in the U.S. of B. thailandensis as B. pseudoma- llei could potentially trigger an unnecessary bioterrorism investigation.

Strain MSMB 43 appears distinct from B. thailandensis, B. pseudomallei, and B. oklahomensis by analysis of MLST sequences, but unexpectedly the percent DNA-DNA hybridization is above the $70 \%$ threshold that fulfills part of the current gold standard for species definition [12].

B. thailandensis is a close relative of $B$. pseudomallei, but is much less virulent in animal models such as hamsters $[1,2]$. Since access to $B$. pseudomalle $i$ is restricted due to its classification as a category B select agent, B. thailandensis and other less virulent related strains may serve as acceptable substitutes for training and research $[13,14]$. B. thailandensis has also been the subject of increased investigation recently, especially in genome sequence comparison studies, to reveal virulence factors in $B$. pseudomallei [14-16].

\section{Conclusion}

We report the isolation and characterization of strain MSMB 43 from bore water in the rural Darwin region of tropical northern Australia. This is the first report of a $B$. thailandensis-like isolate in Australia. Further genomic characterization of MSMB 43 may yield insights into the phylogenetic relatedness of $B$. thailandensis strains and may allow identification of yet undescribed virulence factors in $B$. pseudomallei. The relationship of this isolate to $B$. thailandensis strains from southeast Asia and to endemic Australian Burkholderia species requires further elucidation. The genome of MSMB 43 is currently being fully sequenced along with a collection of $B$. pseudomallei, $B$. mallei and $B$. thailandensis strains from various locations [17]. The sequencing project should help unravel the phylogeny of these Burkholderia and ascertain if MSMB 43 represents environmental Burkholderia species in Australia which are ancestral to both Southeast Asian B. thailandensis and B. pseudomallei. Recent data show that Australian B. pseudomallei strains are probably ancestral to those from southeast Asia $[18,19]$. The origins of $B$. pseudomallei may therefore be linked to environmental Burkholderia species in Australia such as MSMB 43. In addition, comparison of B. pseudomallei and closely related Burkholderia strains collected concurrently from environmental sources may provide further insights into horizontal gene transfer among these species [14].

\section{Methods}

\section{Biochemical testing}

Standard biochemical testing was performed as outlined in Weyant et al [3]. Arabinose assimilation was tested using a minimal salts solution with $10 \% \mathrm{~L}$-arabinose. 


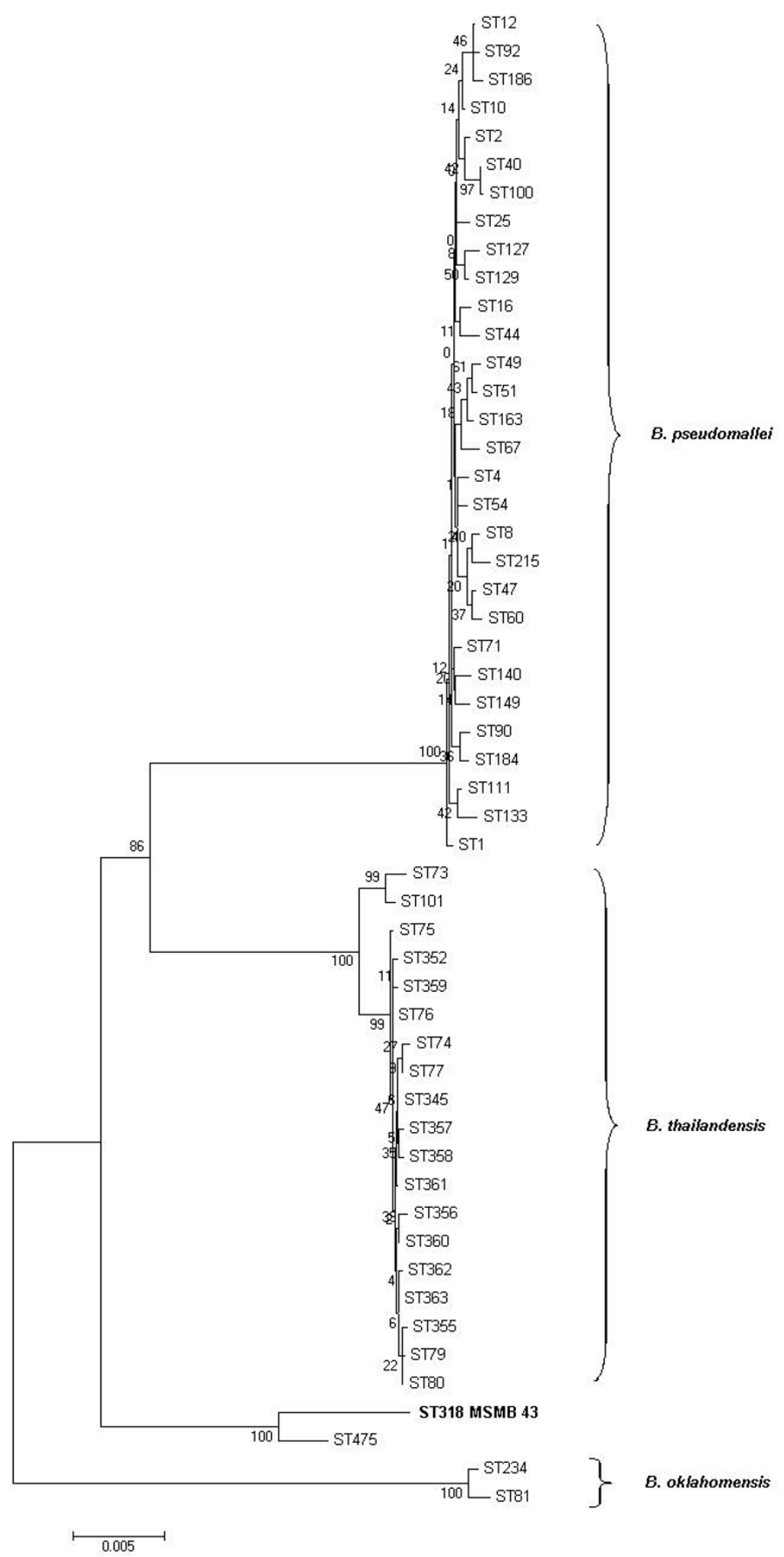

Figure I

MEGA 3.I analysis of concatenated MLST sequences. Strain MSMB $43-$ ST3 8 is compared to a selected subset of STs from the mlst.net database using Neighbor-joining Kimura 2-parameter with 1000 step bootstrap. 
Table I: DNA-DNA hybridization using labeled DNA from MSMB 43 and from the Burkholderia thailandensis type strain.

\begin{tabular}{|c|c|c|c|c|}
\hline \multirow[t]{2}{*}{ Source of unlabeled DNA } & \multicolumn{2}{|c|}{ Results with labeled DNA from B. thailandensis ATCC $700388^{\top}$} & \multicolumn{2}{|c|}{ Results with labeled DNA from strain MSMB 43} \\
\hline & 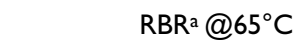 & $\mathrm{D}^{\mathrm{b}}$ & RBRa @65 ${ }^{\circ} \mathrm{C}$ & $D^{b}$ \\
\hline B. thailandensis ATCC $700388^{\top}$ & 100 & 0.0 & 91 & 0.4 \\
\hline MSMB 43 & 91 & 4.0 & 100 & 0.0 \\
\hline
\end{tabular}

aRelative Binding Ratio: the amount of double-stranded DNA formed between labeled and unlabeled DNAs from different strains divided by the amount of double-stranded DNA formed between labeled and unlabeled DNA from the same strain. RBR is expressed as a percentage.

bDivergence within related sequences calculated on the assumption that each $1{ }^{\circ} \mathrm{C}$ decrease in the thermal stability of a DNA duplex is caused by $1 \%$ of unpaired bases within that duplex. $\mathrm{D}$ was calculated to the nearest $0.5 \%$.

\section{DNA preparation}

Whole cell suspensions of bacteria were used for this study as previously described [5]. Bacteria were grown by plating one loop $(1 \mu \mathrm{l})$ of stock cell suspension in defibrinated rabbit blood (stored at $-70^{\circ} \mathrm{C}$ until use) on trypticase soy agar with 5\% defibrinated sheep blood (SBA) (BBL Microbiology systems, Cockeysville, MD) and incubated aerobically $1-2$ days at $37^{\circ} \mathrm{C}$. A single colony was suspended in $200 \mu \mathrm{l}$ of $10 \mathrm{mM}$ Tris, $\mathrm{pH} 8.0$ in a $1.5 \mathrm{ml}$ Millipore $0.22 \mu \mathrm{m}$ filter unit (Millipore, Bedford, MA), heated at $95^{\circ} \mathrm{C}$ for $30 \mathrm{~min}$, and centrifuged at $6000 \times \mathrm{g}$ for $5 \mathrm{~min}$.

\section{I6S rDNA sequencing}

Sequencing and analysis of 1488 bp of the $16 \mathrm{~S}$ rDNA was performed as previously described [5]. In brief, we used the Expand Hi Fidelity PCR system (Roche, Indianopolis, IN). The amplification mix consisted of $1 \times$ buffer \#2, 200 $\mu \mathrm{M}$ dNTP mix, $0.4 \mu \mathrm{M}$ primers F229 and R1908, 5 units Expand Polymerase, and $2 \mu \mathrm{l}$ of cell extract in a total volume of $50 \mathrm{ul}$. Reactions were first incubated for $5 \mathrm{~min}$ at $95^{\circ} \mathrm{C}$. Then, 35 cycles were performed as follows: $15 \mathrm{sec}$ at $94^{\circ} \mathrm{C}, 15 \mathrm{sec}$ at $60^{\circ} \mathrm{C}$, and $1 \mathrm{~min}$ and $30 \mathrm{sec}$ at $72^{\circ} \mathrm{C}$. Reactions were then incubated at $72^{\circ} \mathrm{C}$ for an additional 5 min. PCR products were purified with Qiaquick PCR purification kit (Qiagen, Valencia, CA).

Sequencing primers were chosen from a panel of previously described oligonucleotides [5]. Sequencing was performed using an Applied Biosystems (ABI) BigDye terminator cycle sequencing ver 3.1 kit as per the manufacturer's instructions, except $0.25 \mu$ l of BigDye 3.1 were used for each reaction instead of $8 \mu \mathrm{l}$ (Applied BioSystems, Foster City, CA). Sequencing products were purified by using Centri-Sep spin columns (Princeton Separations, Adelphia, NJ) and were resolved using an Applied Biosystems model 3130xl automated DNA sequencing system (Applied BioSystems, Foster City, CA). BestFit in the Wisconsin package (Accelrys, San Diego) was used to assess the percent identity between sequences.

\section{Multi-locus sequence typing}

We used the panel of primers described on the MLST Web site and in Godoy et al. for both amplification and sequencing [6,7]. For amplification, we used the Expand Hi Fidelity PCR system. Amplification mix consisted of $1 \times$ buffer \#2, $200 \mu \mathrm{M}$ dNTP mix, $0.4 \mu \mathrm{M}$ forward and reverse primers, 0.9 units Expand Polymerase, and $1 \mu$ l of cell extract in a total volume of $25 \mathrm{ul}$. Conditions consisted of an initial $5 \mathrm{~min}$ hold at $95^{\circ} \mathrm{C}$, followed by 35 cycles at $95^{\circ} \mathrm{C}$ for $30 \mathrm{sec}, 60^{\circ} \mathrm{C}$ for $30 \mathrm{sec}$, and $72^{\circ} \mathrm{C}$ for $1 \mathrm{~min}$ with a final hold at $72^{\circ} \mathrm{C}$ for $10 \mathrm{~min}$. PCR products were purified and sequenced as described above for the 16S rDNA sequencing except using the MLST primer set.

To determine relatedness to other Burkholderia strains, the sequences of the seven alleles were concatenated and analyzed using the Neighbor-joining, Kimura 2-parameter method with 1000 step bootstrap in MEGA 3.1 $[6,20]$. BestFit was used to assess the percent identity between concatenated sequences.

\section{DNA/DNA hybridization}

DNA-DNA hybridization was performed using MSMB 43 and the type strain of $B$. thailandensis, strain ATCC $700388^{\mathrm{T}}$. Cells were harvested and lysed, and the chromosomal DNA was isolated and purified as previously described [8]. DNA from strain MSMB 43 and strain ATCC $700388^{\mathrm{T}}$ were labeled with [32P]dCTP using a commercial nick translation kit (Invitrogen Life Technologies, Carlsbad, CA) and tested for reassociation to unlabeled DNA from the same strain (homologous reaction), as well as to each other (heterologous reactions). Relative binding ratios and percent divergence were calculated as described previously [8].

\section{Authors' contributions}

JEG carried out the $16 \mathrm{~S}$ rDNA sequencing, performed analysis of both $16 \mathrm{~S}$ rDNA and MLST, participated in the design of the study, and drafted the manuscript. MBG, DG, and MJM performed biochemical and phenotypic studies. RTN performed MLST and sequence alignment. AS performed DNA/DNA hybridization. PPW and BJC 
participated in the design and coordination of the study. The laboratory of BJC and MJM retrieved and cultured the bore water isolates. All authors read and approved the final manuscript.

\section{Acknowledgements}

We thank Heidi Smith-Vaughan and Yvonne Wood for assistance with bacterial isolation and identification. This publication made use of the Multi

Locus Sequence Typing (MLST) website at Imperial College London developed by David Aanensen and Man-Suen Chan and funded by the Wellcome Trust [7].

\section{Disclaimer}

The findings and conclusions in this report are those of the authors and do not necessarily represent the views of the Centers for Disease Control and Prevention.

\section{References}

I. Brett PJ, DeShazer D, Woods DE: Burkholderia thailandensis sp. nov., a Burkholderia pseudomallei-like species. Int J Syst Bacteriol I 998, $48 \mathrm{Pt} \mathrm{I:317-320.}$

2. Brett PJ, Deshazer D, Woods DE: Characterization of Burkholderia pseudomallei and Burkholderia pseudomallei-like strains. Epidemiol Infect 1997, I I 8(2): | 37-| 48.

3. Weyant RS, Moss CW, Weaver RE, Hollis DG, Jordan JG, Cook EC, Daneshvar MI: Pseudomonas pseudomallei. In Identification of unusual pathogenic gram-negative aerobic and facultatively anaerobic bacteria Edited by: Hensyl WR. Baltimore , Williams \& Wilkins; 1995:486-487.

4. Novak RT, Glass MB, Gee JE, Gal D, Mayo MJ, Currie BJ, Wilkins PP: Development and evaluation of a real-time PCR assay targeting the type III secretion system of Burkholderia pseudomallei. J Clin Microbiol 2006, 44(I):85-90.

5. Gee JE, Sacchi CT, Glass MB, De BK, Weyant RS, Levett PN, Whitney AM, Hoffmaster AR, Popovic T: Use of I6S rRNA gene sequencing for rapid identification and differentiation of Burkholderia pseudomallei and B. mallei. J Clin Microbiol 2003, 4I(10):4647-4654.

6. Godoy D, Randle G, Simpson AJ, Aanensen DM, Pitt TL, Kinoshita R, Spratt BG: Multilocus sequence typing and evolutionary relationships among the causative agents of melioidosis and glanders, Burkholderia pseudomallei and Burkholderia mallei. J Clin Microbiol 2003, 4 I (5):2068-2079.

7. MLST: Burkholderia pseudomallei MLST website. [http:// bpseudomallei.mlst.net/].

8. Brenner DJ, McWhorter AC, Knutson JK, Steigerwalt AG: Escherichia vulneris: a new species of Enterobacteriaceae associated with human wounds. J Clin Microbiol 1982, | 5(6): | | 33- | | 40.

9. Glass MB, Steigerwalt AG, Jordan JG, Wilkins PP, Gee JE: Burkholderia oklahomensis sp. nov., a Burkholderia pseudomalleilike species formerly known as the Oklahoma strain of Pseudomonas pseudomallei. Int J Syst Evol Microbiol 2006, 56(Pt 9):217I-2176.

10. White NJ: Melioidosis. Lancet 2003, 36 I(9370):1715-I722.

II. Cheng AC, Currie BJ: Melioidosis: epidemiology, pathophysiology, and management. Clin Microbiol Rev 2005, 18(2):383-4I6.

12. Wayne LG, Brenner DJ, Colwell RR, Grimont PAD, Kandler O, Krichevsky ML, Moore LH, Moore WE, Murray RGE, Stackebrandt E, Starr MP, Trüper HG: Report of the ad hoc Committee on Reconciliation of Approaches to Bacterial Systematics. Int J Syst Bacteriol 1987, 37:463-464.

13. Rotz LD, Khan AS, Lillibridge SR, Ostroff SM, Hughes JM: Public health assessment of potential biological terrorism agents. Emerg Infect Dis 2002, 8(2):225-230.

14. Yu Y, Kim HS, Chua HH, Lin CH, Sim SH, Lin D, Derr A, Engels R, DeShazer D, Birren B, Nierman WC, Tan P: Genomic patterns of pathogen evolution revealed by comparison of Burkholderia pseudomallei, the causative agent of melioidosis, to avirulent Burkholderia thailandensis. BMC Microbiol 2006, 6:46.
15. Brown NF, Beacham IR: Cloning and analysis of genomic differences unique to Burkholderia pseudomallei by comparison with B. thailandensis. J Med Microbiol 2000, 49(II):993-I00I.

16. Wiersinga WJ, van der Poll T, White NJ, Day NP, Peacock SJ: Melioidosis: insights into the pathogenicity of Burkholderia pseudomallei. Nat Rev Microbiol 2006, 4(4):272-282.

17. NCBI: MSMB43 Genome Sequencing Project. [http:// www.ncbi.nlm.nih.gov/Taxonomy/Browser/wwwtax.cgi?.id=44II57].

18. Cheng AC, Ward L, Godoy D, Norton R, Mayo M, Gal D, Spratt BG, Currie BJ: Genetic Diversity of Burkholderia pseudomallei Isolates in Australia. J Clin Microbiol 2008, 46(I):249-254.

19. Tuanyok A, Auerbach RK, Brettin TS, Bruce DC, Munk AC, Detter JC, Pearson T, Hornstra H, Sermswan RW, Wuthiekanun V, Peacock SJ, Currie BJ, Keim P, Wagner DM: A horizontal gene transfer event defines two distinct groups within Burkholderia pseudomallei that have dissimilar geographic distributions. Journal of bacteriology 2007, $189(24): 9044-9049$.

20. Kumar S, Tamura K, Nei M: MEGA3: Integrated software for Molecular Evolutionary Genetics Analysis and sequence alignment. Brief Bioinform 2004, 5(2): 150-163.
Publish with Biomed Central and every scientist can read your work free of charge

"BioMed Central will be the most significant development for disseminating the results of biomedical research in our lifetime. "

Sir Paul Nurse, Cancer Research UK

Your research papers will be:

- available free of charge to the entire biomedical community

- peer reviewed and published immediately upon acceptance

- cited in PubMed and archived on PubMed Central

- yours - you keep the copyright

Submit your manuscript here:

http://www.biomedcentral.com/info/publishing_adv.asp 